DOI: 10.21767/2254-6081.1000124

\title{
Solitary Muscular Recurrence of Nasopharyngeal Carcinoma
}

\author{
El-Amin Marnouche ${ }^{1}$, Halima Abahssain ${ }^{2}$ and Noureddine Benjaafar ${ }^{1}$ \\ ${ }^{1}$ Department of Radiation Oncology and Radiotherapy, National Institute of Oncology, Rabat, Morocco \\ ${ }^{2}$ Department of Medical Oncology, National Institute of Oncology, Rabat, Morocco
}

Corresponding author: El-Amin Marnouche, Resident of Radiation Oncology and Radiotherapy, National Institute of Oncology, Rabat, Morocco, Tel: +212665096287; E-mail: elaminmarnouche@gmail.com

Received: 06 January 2017; Accepted: 10 January 2017; Published: 16 January 2017

Citation: Marnouche EA, Abahssain H, Benjaafar N. Solitary Muscular Recurrence of Nasopharyngeal Carcinoma. Arch Can Res. $2017,5: 1$.

\section{Case Presentation}

A 55-year-old Moroccan man was treated, two years ago, for nasopharyngeal carcinoma (UCNT: undifferentiated carcinoma of nasopharyngeal type) staged as $\mathrm{T} 2 \mathrm{~N} 2 \mathrm{c} \mathrm{MO}$ according to the seventh edition of the American Joint Committee on Cancer.

The patient received an initial dose of 50 Gy $(2$ Gy per fraction) and a boost dose of $20 \mathrm{~Gy}$ to the primary site by three-dimensional conformal radiation therapy. After prophylactic irradiation to neck lymph nodes (level II to V), electron therapy was used to deliver a boost dose of $18 \mathrm{~Gy}$ (3
Gy per fraction) to the cervical lymphadenopathies. Concomitant chemotherapy based on cisplatin was administrated to the patient.

The patient presented with 6-month history of painless swelling of the left lateral thoracic wall. Physical examination revealed a firm $5 \mathrm{~cm}$ mass, fixed to the deep plane. Computed tomography (CT) of chest showed a soft tissue mass, with necrosis, involving the left serratus anterior muscle $(87 \mathrm{~mm} \times$ $55 \mathrm{~mm} \times 36.7 \mathrm{~mm}$ ). This process involved partially the body of the $6^{\text {th }}$ rib and the contiguous pleura with respect to lung parenchyma (Figure 1).
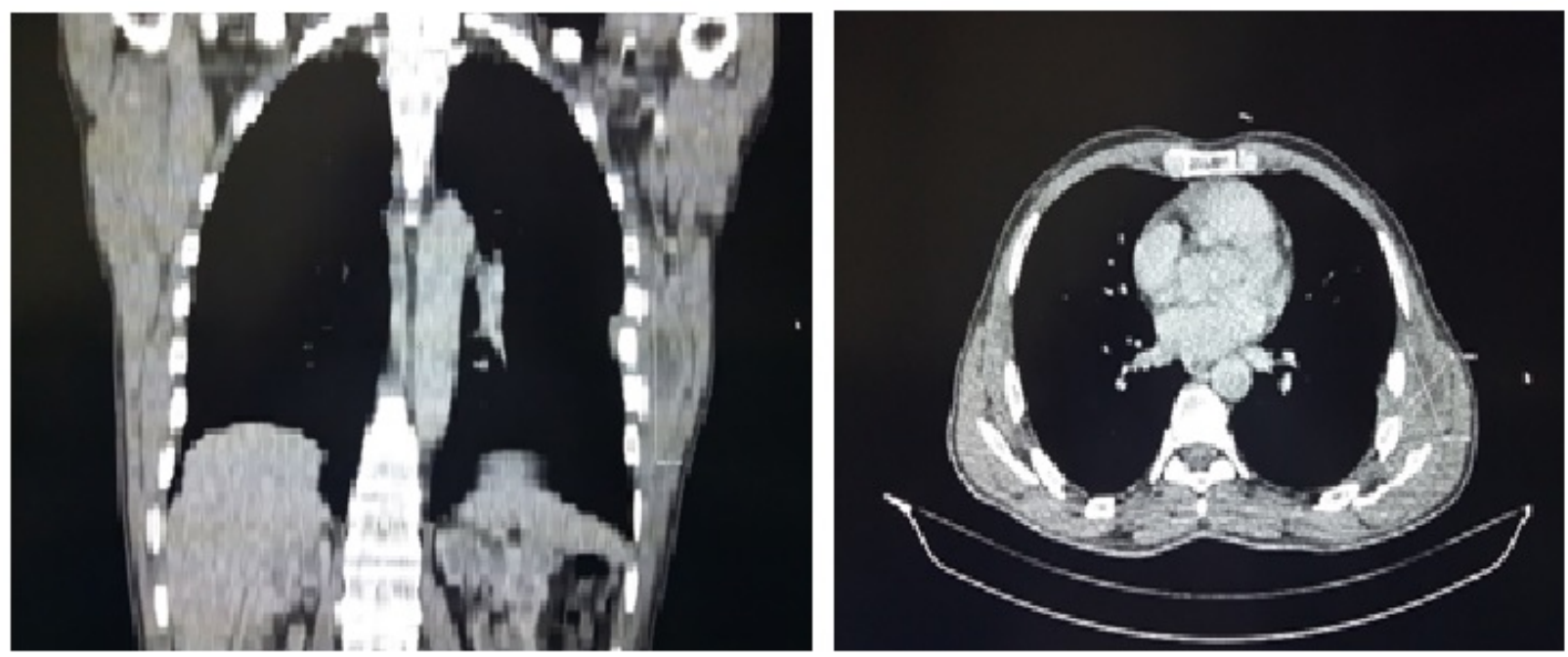

Figure 1 Coronal and axial thoracic CT showing a soft tissue mass involving the left serratus anterior muscle.

Biopsy of the mass was performed and the diagnosis of undifferentiated carcinoma of nasopharyngeal type was confirmed by Immunohistochemistry study [Anti-CK (cytokeratin) 7: negative/ Anti-CK 20: negative/ Anti LMP1 (latent membrane protein): negative/ Anti-P63: positive].
No other recurrences were revealed by bone scan, MRI of head and neck and hepatic ultrasonography. Therefore, patient received palliative chemotherapy with local therapy if shrinkage mass. 